\title{
Serviço social e antropologia: interfaces na formação de assistentes sociais na Amazônia
}

\author{
Maria Socorro Rayol Amoras Sanches \\ Universidade Federal do Pará (UFPA)
}

\author{
Andrea Mello Pontes \\ Universidade Federal do Pará (UFPA)
}

Serviço social e antropologia: interfaces na formação de assistentes sociais na Amazônia

Resumo: Este ensaio objetiva contribuir para crítica, reflexão e aprofundamento do diálogo entre Serviço Social e Antropologia na formação de assistentes sociais na Amazônia, interface importante para o posicionamento político como uma das mediações no âmbito da atuação do assistente social. Menciona aspectos históricos e socioantropológicos do contexto amazônico, tomando como necessárias a explicação, a compreensão, a interpretação das consonâncias e contradições entre particularidades e totalidades da realidade concreta, para que sujeitos sociais sejam reconhecidos e considerados nas matrizes curriculares do curso.

Palavras-chave: Serviço Social. Antropologia. Prática profissional. Amazônia.

Social Service and Anthropology: Interfaces in the education of social workers in the Amazon

Abstract: The purpose of this article is to contribute to a criticism, reflection and deepening of the dialog between social service and anthropology in the education of social workers in the Amazon. This dialog is an important interface for the political positioning of the profession and one of the mediations in the practice of social workers. It mentions historic and socio-anthropological aspects of the Amazonian context, understanding that the explanation, understanding and interpretation of the consonances and contradictions between particularities and totalities of the concrete reality to be necessary, so that social subjects are recognized and considered in the curricular matrixes of the course.

Keywords: Social Service. Anthropology. Professional practice. Amazon. 


\section{Introdução}

Interessa ao curso de serviço social a possibilidade de interlocução com as diversas áreas de conhecimento do campo social, isto é, que na interlocução, constructos teóricos e metodológicos possam apontar caminhos para a intervenção na/com mediações na realidade social. Contudo, o diálogo com a antropologia tem se constituído em tensões nas formulações e nas reformulações dos projetos pedagógicos, a partir da matriz curricular do curso. Enquanto no passado, as ciências sociais, por meio do positivismo, promoveram um diálogo profícuo entre a antropologia e o serviço social, no presente, embora essas disciplinas estejam fundamentadas nas vertentes críticas do conhecimento social, tal diálogo não tem permeado com muita facilidade suas práticas investigativas.

O campo científico, como define Bourdieu (1983, p. 22-23), é o espaço de disputa pelo monopólio da "autoridade científica [...] é um campo de forças e um campo de lutas para conservar ou transformar esse campo de forças". Nessa direção, as ciências da sociedade, como as demais ciências em suas disputas, hierarquizam métodos, técnicas, conceitos, categorias, determinadas teorias e revestem-se de autoria e autoridade, perante o estudo da realidade social. No jogo de forças da academia, é comum se fazer separações e hierarquizações nos concorres e nos enfrentamentos entre campos que perscrutam a crítica das macroestruturas e aqueles que buscam a relativização e a interpretação das relações particularizadas, das subjetividades e das singularidades com vistas à compreensão das singularidades na totalidade, porque, estas, são percebidas como portadoras de temas inaudíveis. Na disputa pelo monopólio, algumas disciplinas vão ocupando lugares marginais, ficando esvaziadas nas franjas das matrizes curriculares que as acolhem, como é recorrente acontecer com a antropologia (BARROS, 2004).

O escopo da antropologia são as "relações sociais" e a atualização da cultura nessas relações, como discute Viveiros de Castro (2002, p. 120): "Não são as relações que variam, são as variações que se relacionam”. A antropologia, portanto, se interessa pelo estudo da diversidade da vida humana e da pluralidade de contextos para interpretar a dinâmica das relações sociais, ou seja, pelo estudo de diferenças e alteridades. No entanto, certos debates, instalados nas disputas do campo científico, como mencionados anteriormente, impedem que o objeto dessa disciplina seja compreendido por muitos cursos que adotam a análise crítica das macroestruturas sociais, de base econômica, em seus projetos políticos curriculares, como é o caso do serviço social, por meio de suas Diretrizes Curriculares Nacionais. Nesse campo de disputa, a perspectiva interpretativa da antropologia tem sido alvo de críticas no sentido de reservar às ciências sociais um caminho de retorno ao conservadorismo, ou seja, de negação da teoria social crítica, como discute Oliveira (2006, p. 95): "Falar em interpretação nas ciências sociais hoje em dia e, sobretudo, na antropologia, é uma temeridade, pois facilmente quem assim o faz pode ser confundido como um defensor de uma 'antropologia interpretativista', comumente chamada de "pós-moderna"'. Embora não haja a intenção de adentrar nos meandres dessa crítica, faz-se a opção por um posicionamento a favor da interpretação como uma perspectiva hermenêutica diacrônica que possibilita desnaturalizar categorias universais, como defende o referido autor, com base nas referências de Paul Ricouer.

$\mathrm{O}$ argumento da interpretação, aqui reivindicado, segue o conceito explorado por Oliveira (2006). O conceito implica explicação e compreensão numa relação dialética de dupla interpretação - interpretação compreensiva -, por meio da qual se procura dar conta de significações apreensíveis por uma abordagem hermenêutica, como explica Oliveira (2006, p. 104): “quando relacionamos explicação e compreensão, porém considerando ambas perfeitamente válidas em proporcionar-nos conhecimento antropológico, estamos assumindo uma postura hermenêutica, moderna dialógica, ou ainda, dialética". É importante dizer que não há tentativa de atribuição de juízos de valor aos campos de estudos em questão, e sim o reconhecimento das diferenças e dissonâncias entre ambos, reafirmando a importância de se discutir a contribuição do diálogo antropológico e do seu posicionamento teórico, ético e político na interpretação das relações e das práticas sociais para o trabalho de intervenção do assistente social. Relações e práticas sociais que realizam por meio de mediações sócio históricas e institucionais, presentes em seu campo de atuação, conforme a concepção adotada pelo serviço social. A mediação no campo investigativo e na prática interventiva do curso, segundo os estudos de Pontes (2010), é uma categoria da teoria social marxista apropriada pelo Serviço Social, a partir da década de 1990, tanto no seu campo investigativo da processualidade histórico-social das problemáticas sociais, quanto do ponto de vista prático - da intervenção -, da práxis, uma ação pautada no projeto ideológico de superação das desigualdades sociais. 
Nesse constructo teórico, portanto, onde residem os campos epistemológicos da antropologia e do serviço social, é importante esclarecer que essa reflexão não se aterá a uma discussão de possibilidades e impossibilidades de interlocução entre métodos que tomam caminhos divergentes nessas disciplinas, pois tal empreendimento exige um estudo de maior fôlego. Nem tampouco enveredará numa discussão para dizer ao serviço social que o seu projeto téorico-metodológico, fruto das lutas políticas da categoria, não é o mais adequado. Isso seria demasiadamente autoritário, prepotente e desonesto.

\section{Ainda para justificar}

Ao se reiterar a importância das Diretrizes Curriculares Nacionais do serviço social e preservar a antropologia de quaisquer ameaças de preconceitos e estereótipos, e de instrumentalismos, superficialismos e empirismos - como muitos tentam restringi-la quando a convidam a compor as matrizes curriculares de outros cursos, isto é, adotando-a como mero instrumento de coleta de dados, desprovida de teoria -, a intenção é tão somente apresentar algumas reflexões do fazer antropológico que possam contribuir com as práticas investigativas e interventivas do assistente social, no sentido de mostrar a importância de um olhar interpretativo compreensivo das refrações da questão social, objeto de estudo definido pelo Serviço Social (NETTO, 1981; 1989; IAMAMOTO e CARVALHO, 1993), mirando suas expressões multifacetadas e infindáveis, entendidas aqui, segundo a perspectiva antropológica, como uma teia de significados tecida pelo próprio sujeito, por meio de suas experiências humanas e onde ele se encontra emaranhado, imbricado e implicado, isto é, a cultura (GEERTZ, 1973).

Então, como pensar a reflexão antropológica na formação do estudante de Serviço Social que não será antropólogo? Como a antropologia pode contribuir com a formação de assistentes sociais sem tornar superficial sua base de fundamentação? A formulação dessas perguntas reside nos debates que interessam à antropologia e ao Serviço Social contemporâneos, tais como: Estado, público e privado, direitos humanos, globalização, cidadania, política, justiça, governo, trabalho, saúde, educação, família, infância, juventude, cidade, campo, migração, diásporas, sociedade civil, envelhecimento/envelhescência, geração, gênero, sexualidades, identidades, transnacionalidades, raça, povos indígenas e populações tradicionais, deslocamentos sociais, manifestações culturais e sociais, entre outros. Mas como articular o debate dessas temáticas em um contexto específico como a Região Amazônica brasileira?

Como dito antes, a intersecção entre antropologia e Serviço Social não é nova. Talvez o seja em sua institucionalização na perspectiva da interlocução como campo epistemológico e posicionamento político, pois, os primórdios desse encontro, por volta dos anos de 1930, marcam o olhar do serviço social sob as lentes de uma antropologia voltada aos desajustes e aos desvios dos pobres, tendo como fim a prática interventiva da moralização e do ajustamento à ordem social. Nos tempos atuais, fruto de uma trajetória de superação dos determinismos, o Serviço Social pauta suas práticas na teoria social crítica, ampliando seu ângulo de visão sobre os sujeitos e as especificidades da vida social. Assim como a antropologia construiu novos referenciais teóricos e metodológicos reconhecedores da agência dos sujeitos e da dinâmica da vida social e cultural.

A defesa da importância da interlocução entre a antropologia e o Serviço Social não significa a diluição entre campos teóricos. Ela é tão somente uma afiliação a um entendimento que compreende o social e o cultural como totalidade das relações (relações de produção, de exploração, de dominação) que os grupos mantêm entre si e em relação aos outros conjuntos. A referência, nesse sentido, é de uma antropologia que diz respeito a tudo que constitui uma sociedade, isto é, ao âmbito do social e do cultural, seus modos de produção econômica, consumo, técnicas, organização política e jurídica, sistemas de parentesco, relações de poder (relações entre posições sociais, faixas etárias, grupos sexuais e outros), sistemas de conhecimento, crenças religiosas, língua, psicologia, criações estatísticas, artísticas e estéticas (LAPLANTINE, 2007).

Atualmente, para o Assistente Social, a construção de estratégias que possibilitem a explicação para intervir na multiplicidade de expressões de uma realidade multifacetada, também tem se constituído em um grande desafio, pois exige a elaboração de propostas de trabalho criativas, capazes de preservar e efetivar direitos a partir de demandas emergentes do cotidiano. Uma atuação que requer o conhecimento dos sujeitos que o Serviço Social alcança, em consonância com a compreensão das particularidades e da totalidade da realidade concreta, algo que se faz pela mediação. Portanto, a ação do assistente social de planejar, executar, avaliar e propor uma determinada política, considerando a dimensão social e cultural, é de fundamental importância para o reconhecimento da diversidade com garantia e efetivação de direitos (MOLJO; CUNHA, 2009). Isso significa considerar singularidades com a exigência necessária da relativização de categorias gerais, teorias e conceitos universalizantes, contudo, sem cair em particularismos e sem eximir-se da crítica necessária para que as diferenças culturais e as contradições sociais sejam evidenciadas. A universalidade em que operam as teorias reprodutivistas tem impossibilitado, por exemplo, que os povos indígenas e os das chamadas 
populações tradicionais - que, na Região Amazônica são predominantes e diversos, e que combinam certas especificidades (quilombolas, reassentados, haliêuticos, rurais, povos da floresta, atingidos por barragens, entre outros) - sejam percebidos para além da vitimização, da vulnerabilidade, da tutela e da exploração. São justamente abordagens desse tipo que têm impedido que tais populações sejam vislumbradas como agentes sociais de um projeto de sociedade particular que os reconheça em sua autoria, autonomia e escolhas.

Sem desconsiderar a produção dos mecanismos de dominação na nossa sociedade hierarquizada, os quais revestem, inexoravelmente, todos os ganhos de capital para os agentes dominantes do campo institucional de sua aquisição, onde esses povos pela via da "violência simbólica" ocupam o lugar da sujeição, compreende-se que, mesmo destituídos desses ganhos, eles são agentes, pois, segundo Bourdieu (1996, p. 44), "os indivíduos são agentes à medida que atuam e que sabem, que são dotados de um senso prático, um sistema adquirido de preferências, de classificações, de percepção". Nesse sentido, eles atribuem significados às suas relações sociais, dinamizam (ordenam e desordenam) a cultura, fazem escolhas e confrontam as ideologias dominantes. Esse entendimento imprime o argumento de que as políticas de garantia de direitos não podem ser de caráter universalista, uma vez que as experiências são diversas, e muito menos pensadas e elaboradas à revelia de seus principais interessados.

$\mathrm{Na}$ Amazônia, precisamente em sua porção brasileira, de fronteiras borradas pelos binômios urbano/rural, periferia/centro, habitam múltiplos sujeitos imersos em dilemas e potencialidades, com histórias e saberes que se atravessam e se transversalizam. São fronteiras dinamizadas pela trajetória de sujeitos que revelam o que essa Amazônia é na sua pluralidade. Nesse sentido, o objetivo deste texto, é possibilitar ao curso de Serviço Social reflexões para sua reaproximação com a antropologia, na perspectiva de um diálogo crítico que contribua com a interpretação compreensiva da demanda local na sua interface com o global, para pautar sua ação e mediações diante da diversidade. É importante mais uma vez fazer referência ao posicionamento defendido neste texto para não haver distorções. O saber antropológico não está proposto aqui como um guia, e sim como ideias, como uma postura hermenêutica, que pode iluminar o olhar e a prática do assistente social na relação com o outro, o interlocutor privilegiado do serviço social, logo, na perspectiva do reconhecimento da alteridade. Todavia, inquestionavelmente, cabe tão somente ao Serviço Social se perguntar como deseja apropriar-se de tais contribuições sem, contudo, perder de vista o que de mais caro a antropologia resguarda: o seu campo teórico, ético e político.

\section{Amazônia como espaço da vida social e de riquezas}

A Amazônia, palco do colonialismo que não cessa, tem a vida social retratada pela violência contra os seus povos e as suas riquezas, clamando por uma justiça social que sabe não ser possível sem a devida justiça ao modo como seus povos desejam continuar vivendo em seus territórios e como mobilizam, historicamente, um conjunto de saberes. Isto é, uma ecologia de saberes amazônicos ameaçados pelas políticas desenvolvimentistas, implantadas desde o último quartel do século passado e que, atualmente, estão a serviço da atual lógica do mercado internacional, balizadas pelas atividades produtivistas, as chamadas comodities, como discute Loureiro (2009).

Enquanto os Estados Unidos foram uma colônia de povoamento, o Brasil foi uma colônia de exploração e, assim, a Amazônia tem sido desde os primórdios da expropriação de suas riquezas. A chegada dos sesmeiros impôs a expulsão dos proprietários legais, isto é, dos nativos que estavam aqui desde sempre, implantou a escravização de africanos com o intento de alcançar o trabalho de larga extensão nessas terras e, vale lembrar, com todas as dificuldades que um estrangeiro pode enfrentar em terras alheias e com toda a violência que marcou esse processo.

Nos anos de 1950, desde o governo de Juscelino Kubitscheck, a economia brasileira cresce na perspectiva de uma economia de capitais multinacionais ou transnacionais, levada a cabo pela ditadura militar nos anos subsequentes. Esse tipo de economia se concentrava no capital oriundo da exploração das grandes riquezas naturais (LOUREIRO, 1989). Nesse cenário industrial internacional, a Amazônia, conhecida há séculos como reservatório das grandes potencialidades minerais, hidrológicas, madeireiras e outras, tornou-se espaço privilegiado para a implantação dos grandes projetos e, hoje, espalhados nos mais diversos pontos dessa região, eles constituem a expressão desse capital. E mesmo sob discursos ambientalistas, esses empreendimentos guardam a mesma feição predatória e avassaladora dos primeiros tempos. Desde então, esses povos, que constituíram a maioria da população amazônica, foram e ainda são alijados da partilha das riquezas, considerando que grande parte dessas riquezas naturais se encontra dentro de seus territórios. Daí a luta pelo território ter se feito luta cotidiana. Ela é processo de territorialização ${ }^{1}$ vivido a ferro e fogo, que os impulsionam a enfrentar o Estado e o capital para reivindicar e acessar direitos. Os chamados povos tradicionais e indígenas, reduzidos drasticamente pelo genocídio e pelo permanente conflito fundiário, mantêm-se em confronto contra velhos e novos modelos de exploração do capital e de exclusão social, os quais, por meio de concessões no âmbito 
estatal, são gerenciados pelas mineradoras, madeireiras, hidrelétricas, siderúrgicas e pelo vampirismo do agronegócio. E aquelas populações que vivem nas confluências com os centros urbanos, mas que ainda guardam suas feições rurais, por sua vez, enfrentam longas batalhas judiciais contra projetos arbitrários de urbanização dos governantes públicos, em parceria com setores privados.

Essas populações, que carregam cosmologias e epistemologias próprias de um modo particular de tessitura de suas relações, são marcadas pelo projeto civilizatório que se incumbiu de projetá-las no lugar do atraso, do improdutivo, da ignorância, ou seja, da incivilidade. Sob os equívocos dos determinismos biológico, sociológico e geográfico, são populações responsabilizadas pelo insucesso econômico que esse país amarga, porque contrariam a lógica da acumulação capitalista; é a colonialidade alimentada e atualizada pelo projeto neoliberal das eficiências e das capacidades produtivas. E com base nessa mesma inteligentística, pautada em definições analíticas unívocas e polaridades fixas e definitivas, abre-se um fosso entre o urbano e o rural por onde emergem parâmetros valorativos que impregnam o olhar do estrangeiro e até mesmo do nativo, interferindo na finalidade e na estrutura organizacional das instituições, bem como nas suas relações cotidianas. A divisão urbano/rural, como Carneiro (2012) problematiza, organiza o modo como se percebe e se pensa aspectos importantes do mundo ao nosso redor. Isso faz com que constantemente sejam atribuídas qualidades urbanas e rurais às pessoas e às coisas, seja na organização administrativa, na formulação de categorias estatística, na classificação das atividades econômicas, seja na formulação de políticas públicas, entre outras. Daí a ideia de limpeza racial - fruto do etnocentrismo gestado nas entranhas do projeto colonial ocidental, que dividiu o mundo entre "selvagens" e "civilizados", como discute Said (2007) - ser ainda tão perseguida e desejada pelas elites empresariais brasileiras e pelos habitantes da outra margem do atlântico, aqueles idealizadores de uma Amazônia natural, rica e produtiva, como em tempos pretéritos.

É possível ver a materialidade dessa intenção quando as particularidades dos povos da Amazônia não são levadas em conta na formulação de políticas públicas e programas sociais, uma vez que reúnem as impressões e as expectativas do colonizador, como mostra Loureiro (2009, p. 21):

\begin{abstract}
a) Um dos traços fundamentais na dominação social da Amazônia brasileira é a persistência de políticas de caráter elitista, patrimonialista e voltadas especificamente para a acumulação do capital, executadas sem qualquer cuidado ou preocupação com a vida e o futuro das populações locais; essas políticas têm sido propiciadoras de uma enorme concentração de capital por grupos econômicos privados nacionais, estrangeiros ou multinacionais; elas resultam na exclusão das populações naturais que habitam a região, - os ribeirinhos, os caboclos, os quilombolas e amplas camadas urbanas da sociedade, que não integram as elites. b) Como decorrência dessas políticas, estabeleceram-se tensões e antagonismos visíveis por parte das elites e do Estado em relação a esses grupos sociais, principalmente os que habitam o interior da região já que, pelas terras que ocupam e por sua relação com a natureza, são considerados como obstáculos ao progresso, cujo modo de viver seria incompatível com a vida moderna. Diante dessa premissa são alijados de processos de 'modernização da região'; por outro lado, esses grupos sociais são barrados, freados em suas pretensões e aspirações de manter suas formas de vida, consideradas pelas elites e pelo Estado como improdutivos ou arcaicas. Daí porque são escorraçados para as periferias urbanas, de modo a liberar as terras que habitam ou trabalham, visando disponibilizar a riqueza natural que elas encerram, e assim beneficiar aqueles que supostamente sabem e podem tirar delas o maior proveito econômico.
\end{abstract}

A população da Amazônia é constituída pela diversidade étnica e a pobreza, tal como compreende o Serviço Social ${ }^{2}$ e espalhada nessa região - seja no campo, na floresta, nas ilhas e nas bordas das cidades - é vivenciada por grupos étnicos. Esses grupos são agentes de um longo processo histórico de construção de identidades coletivas, dinamizado tanto pela imposição do projeto colonial quanto pelas escolhas individuais e permissões grupais, a exemplo daquelas na forma de estratégia de luta e de enfrentamento a esse projeto, onde denunciam a tese da democracia racial, anunciada por Freyre (2000), no solo amazônico. A ideia de uma democracia racial é desconstruída, entre outras coisas, pelos crimes cometidos contra os povos da Amazônia, aqueles compreendidos como crimes de racismo ambiental ${ }^{3}$. Apesar de ser um conceito cunhado recentemente, a existência dele é antiga. O que o agrava é o aperfeiçoamento de seus dispositivos nos tempos atuais. Aperfeiçoamento que não acompanha a atualização das leis para sua punição e, por isso, as periferias na Amazônia têm crescido de modo vertiginoso nas últimas décadas. Assim, admitir a amplitude das populações das periferias da Amazônia, significa dizer que, nesses espaços, existem práticas pujantes de um modo diverso de ser e de viver nessa região, estas que evidenciam questões de classes e raça, um par que não se desvincula na antropologia para pensar outras dimensões, marcadores e categorias sociais. Não é possível, portanto, referir-se às práticas sociais dessa população no singular, nem tão somente vislumbrá-las como determinadas por "relações de produção", mas, considerá-las numa aproximação com Bourdieu (2003) e Mauss (2003), que as inserem em campos relacionais e fatos sociais totais ${ }^{4}$. 
Há tempos que o movimento social, organizações, entidades, representações e associações populares denunciam a invisibilidade das populações amazônicas nas políticas que intentam garantir os direitos básicos nessa região, uma vez que nunca são chamadas para discutir e propor as suas soluções e encaminhamentos. A formulação de políticas públicas reconhecedoras das peculiaridades dessas populações implica rompimento com o velho modelo de ajuste às normas gerais, supostamente igualitárias e democráticas que, com frequência, vão de encontro a seus interesses e expectativas, de modo que os amazônidas são tratados em condições de inferioridade, ou seja, com políticas residuais, excludentes e acidentais. A Amazônia vivida pela pluralidade dos grupos humanos é insignificante perante aquela usufruída pelos donos do capital nacional e internacional. Para eles, é o habitat da maior biodiversidade do mundo, isto é, das riquezas que a indústria precisa. Por isso, é tão comum encontrar nessa região políticas bem intencionadas, mas que estão longe de terem, como preocupação primeira a vida dos povos amazônicos e sua autonomia econômica.

Por mais que os índices oficiais não indiquem que essas populações são os pobres da Região Amazônica, é inquestionável tal fato. Nesse caso, para a intervenção do Serviço Social em um contexto específico, precisamente pela perspectiva dialógica da interpretação compreensiva, cabe responder: quem são esses povos? Como se veem? Como e onde vivem? Como desejam continuar vivendo? Isto é, aquilo que definem como suas expectativas e projetos de vida. Eleva-se, portanto, a exigência da apreensão de suas categorias nativas por onde expressam suas formas de organização social; suas relações e práticas sociais; seus sentidos de trabalho, de riqueza e de pobreza; suas concepções de família e parentesco; o modo de vivenciar as sexualidades; seus significados de infância, juventude e velhice; os aspectos simbólicos mobilizados por meio de práticas religiosas, de saúde e de cura; o modo de pensar e fazer política; os sentidos que imprimem nas relações de gênero e geracional; o que tomam para si no jogo identitário; e a compreensão do lugar de uma ancestralidade sobre a qual reside o campo epistemológico de seus saberes.

Esse é um caminho, um olhar, que traz para o centro do debate o questionamento de categorias que essencializam a Região Amazônica, a sua população, as suas demandas e suas necessidades. Entretanto, antes de qualquer coisa, o assistente social precisa compreender em situações concretas e particulares, como essas mencionadas, que a etnicidade ${ }^{5}$ nessas terras é evidenciada numa Amazônia de tantas Amazônias. É nesse exercício hermenêutico que podem emergir estratégias profícuas a sua intervenção profissional. Cabe a clareza de que, no processo histórico (em curso) de pauperização dos povos ameríndios e de africanos abrasileirados forçadamente, não decorreu (e não decorre) sem enfrentamentos e embates por direitos diferenciados. Nessa perspectiva, o trabalho de intervenção é ação dialógica de profunda interpretação do lugar de luta dos povos dessa região, que exige chegar até eles e estar entre/com eles, para apreender o campo semântico, onde essas lutas inserem-se, sendo este o caminho proposto pela antropologia via etnografia.

\section{Observar, interpretar e intervir: mediações do/no Serviço Social}

A compreensão da relação sujeito-objeto na construção do fazer do assistente social é de suma importância para sua prática de intervenção, uma vez que a sua aproximação com o outro na vida cotidiana é, para ele, o lócus privilegiado de sua prática profissional, espaço em que se objetivam as relações entre indivíduos e grupos com as suas designações sociais, econômicas, políticas e culturais. Somente o cotidiano compreendido permite ao assistente social identificar as formas como as demandas sociais chegam às instituições.

O espaço de intervenção do Serviço Social, segundo Guerra (1995), constituiu-se a partir da inserção socioprofissional dele na Divisão Social e Técnica do Trabalho posta pela sociedade burguesa madura, ou seja, pelo capitalismo monopolista. Como um ramo de especialização do trabalho coletivo, seu objetivo é dar respostas e buscar soluções à pluralidade de questões que se refratam da Questão Social. Mas, para isso, o assistente social necessita de fundamentos teórico-metodológicos, conhecimentos e saberes interventivos, habilidades técnico-operativas e uma perspectiva ética com clara orientação estratégica.

As determinações econômicas e políticas privilegiadas pelo corte analítico do Serviço Social não podem ser capturadas fora da cotidianidade, sob pena de negar a categoria ontológica e reflexiva de historicidade própria da dialética marxista, contudo, é imprescindível o mergulho nas tessituras das relações e das práticas sociais e humanas em suas múltiplas e particularizadas expressões, pois a Questão Social e suas refrações não são construídas de forma homogênea em todos os contextos sociais. A captura das diferenças e das singularidades inerentes à Questão social não obscurece a complexidade; pelo contrário, é onde ocorre o start intelectivo que revela a plasticidade da particularidade como concreto síntese de múltiplas mediações. Nesse sentido, a antropologia se constitui como um importante campo motivador do olhar percuciente do assistente social, comprometido com a realidade em que trabalha, assim como amplia a habilidade interventiva desse profissional, cuja prática se desborda sobre um campo de tensões institucionais 
descontínuas, onde as lutas entre saberes e as forças políticas estão em jogo, metamorfoseando-se de acordo com as teias relacionais que são construídas nele.

Fernandes (1988), ao refletir sobre o Serviço Social em instituições a partir da prática, observa a dinâmica de um campo relacional que se mostra perante a atuação do assistente social. Esse campo está situado na contradição entre o comportamento individual e grupal de um lado, e as instituições e normas que se colocam de outro, isto é, "no ponto em que aquilo que efetivamente acontece não é o regulamentado, o esperado, o exigido" (FERNANDES, 1988, p. 109). Logo, a instituição é um espaço prenhe das expectativas de seus agentes, onde o assistente social tem o desafio de operacionalizar as informações obtidas de modo a transformálas em questões que permitam a ele conhecer e agir na realidade. Assim, para a autora, é no interior das organizações que se percebem as contradições da sociedade contemporânea, visto que são em seus diferentes tipos de relações que se destroem ou que se constroem as relações do campo democrático. Nelas, uma trama de leis é tecida desde a sua concepção, como menciona Fernandes (1988, p. 112):

\begin{abstract}
Vai-se organizando e reorganizando o espaço, vai-se alargando ou restringindo o campo de trabalho, tudo isto num processo que é simultaneamente histórico, político, social econômico e cultural. Múltiplas lógicas se cruzam em cada instituição e fazem dela um fenômeno social total. [...] Assim, o espaço da instituição não é somente o espaço do instituído, do normatizado e o do pensado; é também o espaço do vivido, do esperado e do desejado. São duas tramas que se sobrepõem: a da atividade institucional e organizacional e a do desejo de todos os intervenientes. São dois códigos distintos da mesma mensagem. É da leitura de ambos, do constante decifrar das suas contradições que se pode entender a totalidade, o aspecto dinâmico daquela realidade. Aquilo que o desejo trama, interfere com o definido e o planejado.
\end{abstract}

Para a interpretação da complexidade das tramas que envolvem o estabelecido, o instituído, o vivido e o desejado, no âmbito das instituições onde atua o assistente social, sensivelmente descritas por Fernandes (1988), a antropologia oferece a sua compreensão da relação sujeito-objeto na apreensão dos fenômenos sociais para a construção do conhecimento, sustentada pelo campo teórico-metodológico do fazer etnográfico. A etnografia é uma importante categoria de pensamento, é performance, meio pelo qual se revela o sentido do ofício, do fazer do antropólogo e que implica auto reflexividade social, visto que, ao observar a cultura nativa, o antropólogo alcança o seu próprio campo cultural (MAUSS, 2003). A etnografia cumpre sua finalidade quando "desnaturaliza" categorias generalizadas e generalizantes, as quais essencializam as relações. Como ressalta Peirano (1995, p.135-136): "a pesquisa etnográfica é o meio pelo qual a teoria antropológica se desenvolve e se sofistica quando desafia os conceitos estabelecidos pelo senso comum no confronto entre a teoria que o pesquisador leva para o campo e a observação da realidade 'nativa' com a qual se defronta". Logo, não é possível reduzir a etnografia a uma técnica, a um instrumento de coleta de dados, isto é, a "um mero descrever de atos presenciados ou (re)contados - a boa etnografia leva em conta o aspecto comunicativo essencial que se dá entre o pesquisador e o nativo, o 'contexto da situação', que revela os múltiplos sentidos dos encontros sociais" (PEIRANO, 2002. p. 11).

Diante do campo epistemológico do saber antropológico, as reflexões aqui propostas estão norteadas na seguinte pergunta: como a antropologia pode contribuir com a formação de assistentes sociais na Amazônia brasileira, no sentido de possibilitar a esse profissional, a partir da interpretação das diferenças, a reflexão do "contexto da situação" para construir sua intervenção? Como ela pode ajudá-lo a constituir-se em um agente profissional interessado em evidenciar as peculiaridades dessa população, mitigada nas tramas das relações cotidianas das instituições. São povos invisibilizados pelas políticas públicas que homogeneízam suas necessidades e descaracterizam suas histórias e diferenças, negando a cidadania?

As diferenças, na perspectiva da alteridade, são o que interessa ao saber antropológico. Contudo, vale ressaltar que o campo epistemológico das diferenças na antropologia não é o mesmo no Serviço Social. Enquanto para a antropologia a diferença ocorre no plano das singularidades, para o Serviço Social acontece no plano das desigualdades econômicas. O campo epistemológico do Direito, um dos parceiros mais próximos do Serviço Social, entende a perspectiva das singularidades como um impeditivo para as políticas de garantia de direitos, pois este não opera com as particularidades e sim com as desigualdades (ALVES; BARROS, 2006). Argumento esse que também é adotado pelo curso de Serviço Social para manter sua opção de análise das desigualdades. Como bem argumenta Velho (1978, p. 2), para o saber antropológico não cabe negar ou invalidar ideologicamente o preceito teórico da universalidade, e sim relativizar e problematizar as construções universais, as "Leis tendenciais históricas" pela observação densa do campo das determinações, como enfatiza: "captar vivências e experiências particulares exige um mergulho em profundidade difícil de ser precisado e delimitado em termos de tempo". Nesse sentido, tanto as desigualdades quanto as diferenças não serão evidenciadas se não houver a desnaturalização de categorias universais, o estranhamento do familiar e o entendi- 
mento de que as relações não são determinadas, e sim construídas socialmente. Todo esse exercício, como explica Peirano (1995, p. 28; 55), é possível pela "prática etnográfica - artesanal, microscópica e detalhista que traduz, como poucas outras, o reconhecimento do aspecto temporal das explicações". É nesse sentido que, para a antropologia, "a diferença produz uma teoria política".

Em uma sociedade hierarquizada como a brasileira, os sistemas de poder e de dominação operam para mapear, organizar e selecionar. Cada categoria social tem o seu lugar posicionado com referência em estereótipos, preconceitos e exclusões, como exemplo, o amazônico, tido como caboclo, isto é, no sentido de incivilizado, e, por isso, improdutivo. As hierarquias são mapeadas a partir das expectativas construídas acerca das pessoas e de seus grupos, aquilo que se espera que sejam ou que se tornem. Essa é a faceta da distribuição desigual do poder em uma sociedade de classes, daí as desconexões entre o estabelecido, o instituído, o vivido e o desejado no interior das instituições. Pelas hierarquias se esquadrinha, se isola e se nomeia, ou seja, ao se naturalizar categorias sociais, se reforçam aquelas que dão continuidade aos sistemas de dominação, como reflete Velho (1978, p. 12):

O processo de estranhar o familiar torna-se possível quando somos capazes de confrontar intelectualmente, e mesmo emocionalmente, diferentes versões e interpretações existentes a respeito de fatos, situações. O estudo de conflitos, disputas, acusações, momentos de descontinuidade em geral é particularmente útil, pois, ao se focalizarem situações de drama social, pode-se registrar os contornos de diferentes grupos, ideologias, interesses, subculturas, etc., permitindo remapeamentos da sociedade. O estudo do rompimento e rejeição do cotidiano por parte de grupos ou indivíduos desviantes ajuda-nos a iluminar, como casos limites, a rotina e os mecanismos de conservação e dominação existentes.

Mas quem é o nativo? O nativo é um sujeito da sua cultura ou, como observa Viveiros de Castro (2002, p. 119), "O nativo é, sem dúvida, um objeto especial, um objeto pensante ou um sujeito. Mas se ele é objetivamente um sujeito, então, o que ele pensa é um pensamento objetivo". No fazer antropológico, o nativo é o pesquisado, contudo, o pesquisador ao olhar para o nativo manipula as lentes por onde olha sua própria cultura e: "Essa relação é uma relação de sentido", ou, como se diz quando o pesquisador pretende à ciência, "uma relação de conhecimento". Portanto, o pesquisador e o nativo "são entidades de mesma espécie e condição: são ambos humanos, e estão ambos instalados em suas culturas respectivas, que podem, eventualmente, ser a mesma". A diferença é que o pesquisador comparece com a sua cultura de pesquisador, ou seja, ele "usa necessariamente sua cultura; o nativo é suficientemente usado pela sua" (VIVEIROS DE CASTRO, 2002, p. 113-114).

\section{Considerações finais}

Como pensar o lugar da antropologia na matriz curricular de formação de assistentes sociais da, na e para a Amazônia, ou seja, no e para o lugar onde vivem suas rotinas, o familiar, considerando também as especificidades de alunas e alunos com entrada pelo processo seletivo diferenciado para indígenas e quilombolas? Como início de uma possível resposta, faz-se a defesa do argumento de que a análise e a descoberta do familiar exigem a desnaturalização dos mapeamentos, o estranhamento, sob a interpretação do ponto de vista do nativo, e daquilo que aos nossos olhos, parece familiares, pois a familiaridade não significa conhecimento.

Assim, observar, interpretar e intervir, colocados aqui entre as mediações do e no Serviço Social para o fazer do assistente social, profissional que também nutre sua prática com a pesquisa, constituem no trabalho constante de decifrar as contradições presentes nas dinâmicas das relações sociais para compreender a totalidade de uma dada realidade social. Desse modo, o familiar, com o necessário exercício de relativizações, é peça importante, ou seja, é objeto relevante para a interlocução entre a antropologia e o serviço social. A Interlocução, destarte, visa à interpretação da mudança social para a construção de ações interventivas com a participação democráticas de seus protagonistas, como observa Velho (1978, p. 13): "não apenas ao nível das grandes transformações históricas, mas como resultado acumulado e progressivo de decisões e interações cotidianas".

\section{Referências}

ALMEIDA, A. W. B. Antropologia dos arquivos da Amazônia. Rio de Janeiro: Casa 8/ Fundação Universidade da Amazônia, 2008. ALVES, A. M.; BARROS, M. M. L. de. Quando o pobre é o "outro". Artigo decorrente do recebimento do prêmio ABA/Ford projetos inovadores no ensino da Antropologia, edição II 2006. Disponível em: htpps://www.abant.org.br/file?id=43. Acesso em: 25 jul. 2016. BARROS, M. M. L. de. Até onde vai o olhar antropológico? Ilha, Florianópolis, v.6, n. 1 e n. 2, p. 145-163, jul. 2004. 
BOURDIEU, P. Le champ scientifique. Actes de La Recherche en Sciences Sociales. 1976. Tradução de Paula Montero. In: ORTIZ, R. Bourdieu: sociologia. São Paulo: Ática, 1983.

. Razões práticas: sobre a teoria da ação. São Paulo: Papirus, 1996.

O poder simbólico. Rio de Janeiro: Bertrand Brasil, 2003.

CARNEIRO, M. J. Ruralidades contemporâneas: modos de viver e pensar o rural na sociedade brasileira. Rio de Janeiro: Manuad X; FAPERJ, 2012.

FERNANDES, M. M. L. Serviço Social em Instituição: algumas reflexões a partir da prática. Revista Serviço Social e Sociedade, São Paulo, v. 9, n. 28, p. 100-117, dez. 1988.

FREYRE, G. Casa grande \& senzala. Rio de Janeiro: Record, 2000.

GEERTZ, C. A interpretação das culturas. Rio de Janeiro: Zahar, 1973.

GUERRA, Y. A instrumentalidade do serviço social. São Paulo: Cortez,1995.

IAMAMOTO, M. V.; CARVALHO, R. de. Relações sociais e serviço social no Brasil:

esboço de uma interpretação histórico-metodológica. São Paulo: Cortez, 1993.

LAPLANTINE, F. Aprender antropologia. São Paulo: Brasiliense, 2007.

LOUREIRO, V. R. A Amazônia no século XXI: novas formas de desenvolvimento. São Paulo: Empório do Livro, 2009.

. A História Social e Econômica da Amazônia. In: PARÁ. Secretaria de Estado de Educação. Estudos e problemas Amazônicos: história social e econômica e temas especiais. Belém, IDESP: 1989.

MAUSS, M. Sociologia e antropologia. São Paulo: Cosac Naify, 2003.

MOLJO, C.; CUNHA, A. M. Serviço Social e Cultura: considerações acerca das concepções de cultura na trajetória da profissão no Brasil desde a sua gênese até os anos 1990. Libertas online, Revista da Faculdade de Serviço Social da UFJF, Juiz de Fora, v.4, n.1, p. 78-104, jul./dez. 2009. NETTO, J. P. Crítica conservadora à reconceituação. Revista Serviço Social \& Sociedade, São Paulo, n. 5, p. 59-75, ago. 1981.

OLIVEIRA, R. C. de. O trabalho do antropólogo. São Paulo: UNESP, 2006.

PACHECO, T. Desigualdade, injustiça ambiental e racismo: uma luta que transcende a cor. In: SEMINÁRIO CEARENSE CONTRA O RACISMO AMBIENTAL, 2006. Fortaleza. Anais... Fortaleza-CE, 2006.

. Cinco Notas a propósito da "Questão Social”. Temporalis/ABEPSS, Brasília, v. 2, n.3, p. 41-49, jan./jun. 2001.

PEIRANO, M. O dito e o feito: ensaios de antropologia dos rituais. Rio de Janeiro: Relume-Dumará; Núcleo de Antropologia da Política; UFRJ, 2002.

A favor da etnografia. Rio de Janeiro: Relume-Dumará, 1995.

PONTES, R. Mediação e serviço social: um estudo preliminar sobre a categoria teórica e sua apropriação pelo serviço social. São Paulo: Cortez: 2010.

SAID, E. Orientalismo: o Oriente como invenção do Ocidente. São Paulo: Companhia das Letras, 2007.

VELHO, G. Observando o familiar. In: NUNES, E. de O. A aventura sociológica. Rio de Janeiro: Zahar, 1978. p. 36-46.

VIVEIROS DE CASTRO, E. de. O nativo relativo. Mana, v. 8, n. 1, p. 113-148, ago. 2002.

\section{Notas}

1 O processo de territorialização é resultante de uma conjunção de fatores que envolvem a capacidade mobilizatória em torno de uma política de identidade e certo jogo de forças em que os agentes sociais, por meio de suas expressões organizadas, travam lutas e reivindicam direitos doEstado. As relações comunitárias nesse processo também se encontram em transformação, descrevendo a passagem de uma unidade afetiva para uma unidade política de mobilização, ou de uma existência atomizada para uma existência coletiva. Achamada "comunidade tradicional” se constitui nessa passagem (ALMEIDA, 2008, p. 118).

2 Referimo-nos à pobreza, conforme entendimento adotado pelo Serviço Social, aquela provocada pelo conflito histórico entre capital e trabalho, fruto de políticas econômicas antidemocráticas, segregadoras e excludentes, como expressão da questão social (NETTO, 2001).

3 "Chamamos de Racismo Ambiental às injustiças sociais e ambientais que recaem de forma desproporcional sobre etnias vulnerabilizadas [...] O Racismo Ambiental não se configura apenas através de ações que tenham uma intenção racista, mas igualmente através de ações que tenham impacto racial, não obstante a intenção que thes tenha dado origem” (PACHECO, 2006, p. 10).

4 Para Bourdieu (2003, p. 179): "campo, no seu conjunto, define-se como um sistema de desvio de níveis diferentes e nada, nem nas instituições ou nos agentes, nem nos atos ou nos discursos que eles produzem, têm sentido senão relacionalmente, por meio do jogo das oposições e das distinções”. Para Mauss (2003, p. 187): “Nesses fenômenos sociais 'totais’ [...] exprimem-se, de uma só vez, as mais diversas instituições: religiosas, jurídicas e morais - estas sendo políticas e familiares ao mesmo tempo -; econômicas - estas supondo formas particulares da produção e do consumo, ou melhor, do fornecimento e da distribuição-; sem contar os fenômenos estéticos em que resultam esses fatos e os fenômenos morfológicos que essas instituições manifestam".

5 Valemo-nos das discussões de Oliveira (2006, p. 136) para compreender a etnicidade como "um espaço social, interno a um determinado país, onde as etnias existentes mantêm relações assimétricas; sendo, nesse sentido, 'essencialmente uma forma de interação entre grupos culturais operando dentro de contextos sociais comuns'. Eu ainda acrescentaria que pelo menos uma dessas etnias desfrutaria de um poder emanado de um Estado, de cuja constituição tal etnia participaria de forma majoritária”. 


\section{Maria Socorro Rayol Amoras Sanches}

samoras@ufpa.br

Doutora em Antropologia pelo Instituto de Filosofia e Ciência Humanas da Universidade Federal do Pará (IFCH)

Professora de Serviço Social da Universidade Federal do Pará (UFPA)

\section{Andrea Mello Pontes}

amello@ufpa.br

Doutora em Antropologia Social pela Universidad Complutense de Madrid

Professora de Serviço Social da Universidade Federal do Pará (UFPA)

\section{UFPA}

Rua: Augusto Corrêa, $n^{\circ} 01$

Belém - Pará - Brasil

CEP: 66075-110 